\title{
Radiation Output Failure
}

National Cancer Institute

\section{Source}

National Cancer Institute. Radiation Output Failure. NCI Thesaurus. Code C133569.

Problem associated with the absence of radiation output from radiological or diagnostic devices. 